\title{
The vegetative state/unresponsive wakefulness syndrome: a systematic review of prevalence studies
}

\author{
W. S. van Erp ${ }^{a, b}$, J. C. M. Lavrijsen ${ }^{a}$, F. A. van de Laar $^{a}$, P. E. Vos ${ }^{c}$, S. Laureys ${ }^{b}$ and \\ R. T. C. M. Koopmans ${ }^{a}$ \\ ${ }^{a}$ Department of Primary and Community Care, Centre for Family Medicine, Geriatric Care and Public Health, Radboud University \\ Medical Centre, Nijmegen, The Netherlands; ${ }^{b}$ Cyclotron Research Center \& Neurology Department, Coma Science Group, University of \\ Liège, Liège, Belgium; and ${ }^{\mathrm{c}}$ Department of Neurology, Slingeland Hospital, Doetinchem, The Netherlands
}

\section{Keywords: \\ disorders of \\ consciousness, \\ epidemiology, postanoxic \\ encephalopathy, \\ rehabilitation, vegetative \\ state}

Received 14 January 2014

Accepted 5 May 2014

\begin{abstract}
One of the worst outcomes of acquired brain injury is the vegetative state, recently renamed 'unresponsive wakefulness syndrome' (VS/UWS). A patient in VS/UWS shows reflexive behaviour such as spontaneous eye opening and breathing, but no signs of awareness of the self or the environment. We performed a systematic review of VS/UWS prevalence studies and assessed their reliability. Medline, Embase, the Cochrane Library, CINAHL and PsycINFO were searched in April 2013 for crosssectional point or period prevalence studies explicitly stating the prevalence of VS/ UWS due to acute causes within the general population. We additionally checked bibliographies and consulted experts in the field to obtain 'grey data' like government reports. Relevant publications underwent quality assessment and data-extraction. We retrieved 1032 papers out of which 14 met the inclusion criteria. Prevalence figures varied from 0.2 to $6.1 \mathrm{VS} / \mathrm{UWS}$ patients per 100000 members of the population. However, the publications' methodological quality differed substantially, in particular with regards to inclusion criteria and diagnosis verification. The reliability of VS/UWS prevalence figures is poor. Methodological flaws in available prevalence studies, the fact that $5 / 14$ of the studies predate the identification of the minimally conscious state (MCS) as a distinct entity in 2002, and insufficient verification of included cases may lead to both overestimation and underestimation of the actual number of patients in VS/UWS.
\end{abstract}

\section{Introduction}

For patients surviving severe brain damage of either traumatic or non-traumatic origin, one of the worst possible outcome is the vegetative state, recently renamed 'unresponsive wakefulness syndrome' (VS/ UWS) [1]. A patient in VS/UWS shows reflexive behaviour such as spontaneous eye opening and breathing, but no signs of awareness of the self or the environment $[2,3]$.

While science is steadily unravelling the physiological basis of disorders of consciousness [4], the number of patients in VS/UWS remains unclear; the most commonly cited prevalence figures are based on estimates $[5,6]$. This is partly due to diagnostic difficulties, reflected in a high misdiagnosis rate: up

Correspondence: W. S. van Erp, Department of Primary and Community Care, Centre for Family Medicine, Geriatric Care and Public Health, Radboud University Medical Centre, Code 117 ELG, P.O. Box 9101, 6500 HB Nijmegen, The Netherlands (tel.: 0031-629194472; fax: 0031-243541862; e-mail: willemijn.vanerp@radboudumc.nl). to $43 \%$ of patients presumed to be in VS/UWS turn out to be at least in a minimally conscious state (MCS)[7] when examined by means of a structured assessment scale [8,9]. The difference between MCS and VS/UWS is of considerable clinical relevance: patients in MCS appear to have a better prognosis [10-12] and to process emotional, auditory and noxious stimuli in a way very similar to that of healthy individuals $[13,14]$.

Epidemiological data form the basis of insight in every clinical condition. In order to apprehend the impact of a disease or syndrome, the number of patients it affects is one of the first things clinicians, scientists and policy makers need to know. The prevalence of VS/UWS, a condition often referred to as 'a fate worse than death' [15], is therefore relevant to epidemiologists, neurologists, primary care physicians, physiatrists, ethicists and policy makers. This paper gives an extensive overview of VS/UWS prevalence figures and their reliability by means of a systematic review. 


\section{Methods}

A literature search of Medline, Embase, the Cochrane Library, CINAHL and PsycINFO was carried out in April 2013, using complete timescales and no language restrictions or other limits. We used the following search terms: 'vegetative state', 'unresponsive wakefulness syndrome', 'apallic syndrome' and 'akinetic mutism', combined with search terms for epidemiology (Appendix S1). Experts in the field were asked for socalled grey data, e.g. governmental reports or personal communications possibly containing VS/UWS prevalence figures.

Titles and abstracts were scanned for relevance by two researchers (WvE, JL) independently. Whenever at least one of the researchers considered a paper relevant or possibly relevant, it was read full text. Publications were included provided they were original cross-sectional point or period prevalence studies, explicitly stating the number of VS/UWS patients within the general population. We excluded studies that concerned only VS/UWS due to degenerative and other non-acute causes, outcome studies within populations with specific medical characteristics (e.g. outof-hospital cardiac arrest, subarachnoid hemorrhage), and papers post-dating 1994 not using the Multi-Society Task Force on PVS-criteria [3]. The latter criterion, however, was dropped as it soon turned out to exclude nearly all otherwise eligible publications.

Upon inclusion, both researchers independently assessed study quality in a structured manner (Appendix S2), based on an earlier systematic review of prevalence studies [16] and two methodological papers $[17,18]$. In short, we looked at study design, whether a point or period prevalence was obtained, response rates in case of questionnaires, the way estimates were constructed and the manner of diagnosis verification in included cases. Although no gold standard for the diagnosis of VS/UWS exists, expert opinions agree that a validated assessment tool for the level of consciousness after the acute phase should be used, preferably the Coma Recovery Scale- revised [19-21]. Repeated assessments and the involvement of proxies and professionals familiar with the patient are recommended [22-24]. Complementary diagnostics like fMRI and EEG could be considered as well $[24,25]$. Next to these items, we checked whether authors mentioned the presence of consensus about the diagnosis in included cases.

When needed in the process of quality assessment, agreement was reached through discussion. As one researcher (JL) was the author of one of the publications [26], a third, independent researcher (FvL) carried out quality assessment in this case. We recalculated absolute patient numbers to prevalence per 100000 people if demographic data from the period concerned were available on www.oecd.org.

\section{Results}

The search strategy and consultation of three experts in the field produced 1001 unique records. Of every publication considered relevant or possibly relevant by one or both authors $(n=107)$, including 31 additional titles from bibliographies, full text was evaluated for eligibility. In four out of 107 cases we were unable to obtain the original publication [27-30], despite attempts to contact the authors. A further 89 papers were discarded as their full texts did not meet inclusion criteria. Finally, 14 studies were included. A flow chart of the selection procedure is shown in Figure 1 and study characteristics can be found in Table 1 .

Over the past 40 years, 14 prevalence studies on VS/UWS were found to have been published, originating from Japan, the Netherlands, France, the USA, Denmark, Austria and Italy. The average year of publication was 1996 (range 1976-2011). We will discuss the studies' methodological characteristics and the prevalence figures they led to.

Researchers used various strategies to identify patients, from questionnaires to the members of the Child Neurology Society [31] to insurance registries [32] and phone interviews with nursing homes' medical directors [26]. In prevalence studies based on questionnaires, response rates turned out fairly high (78$100 \%$ ) with the exception of a $26 \%$ response in a survey amongst members of the Child Neurology Society [31]. Information about non-responders was lacking in all cases. Three papers based on surveys did not mention response rates [33-35]. Sampling frames (i.e. the populations in which the prevalence was investigated) were countries or smaller geographical regions. It should be noted that 2 papers based their prevalence on the nursing home population exclusively [26,36], and that none of the studies included patients being cared for at home. Demographic and socioeconomic variables possibly affecting the samples were described in none of the studies. The two papers in which results from a smaller sample were extrapolated to a nationwide prevalence figure gave no indication of corrections for sample bias [37,38]. Estimates in these and other studies came without confidence intervals [31,32,37-40].

Eight studies [26,35-37,40-43] were carried out after the publication of internationally accepted diagnostic criteria for VS/UWS [3]; three of them also used these as their inclusion criteria $[26,36,44]$. Nine prevalence studies $[31,33,34,37,39,41,42,45,46]$ took place before 


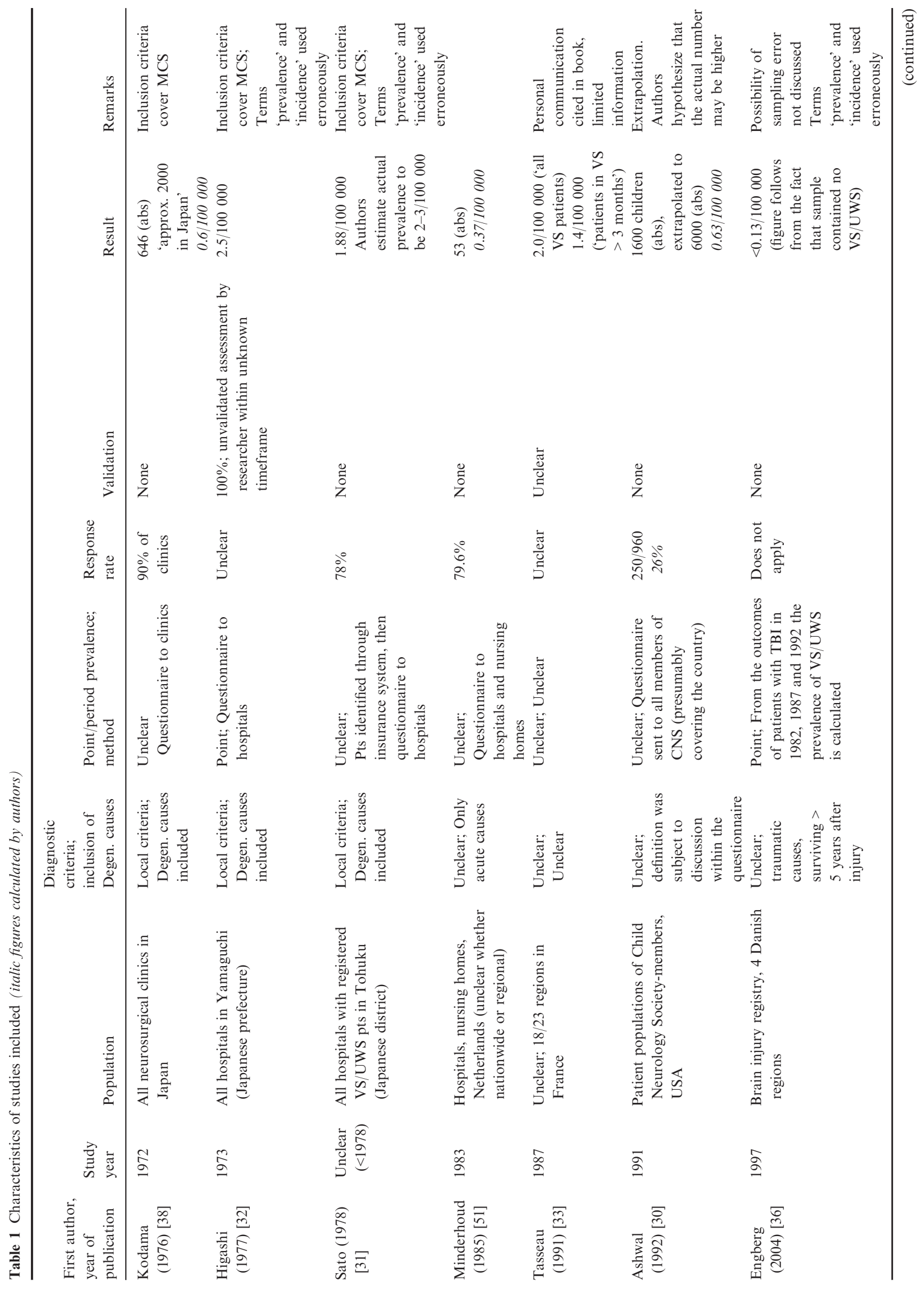




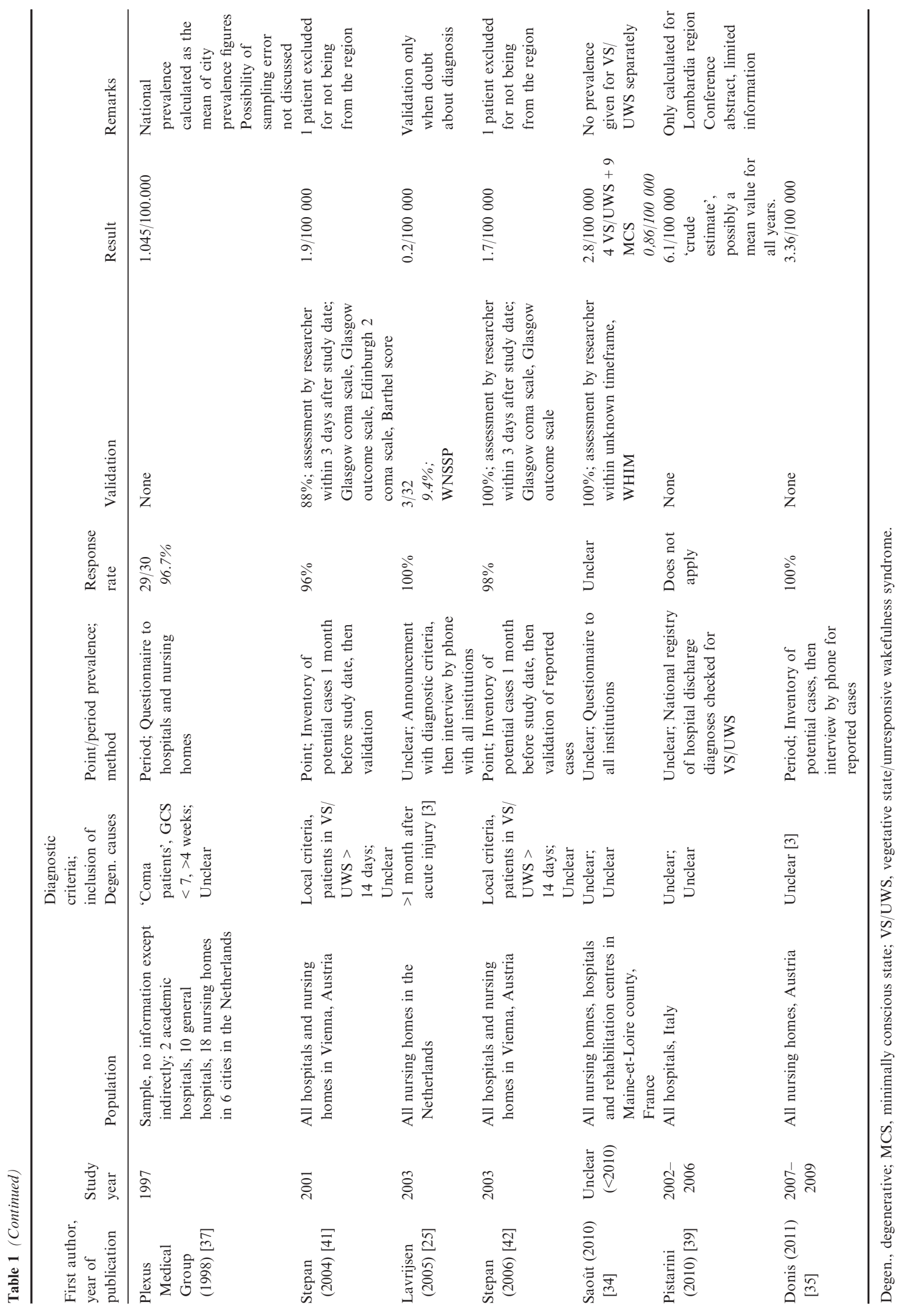




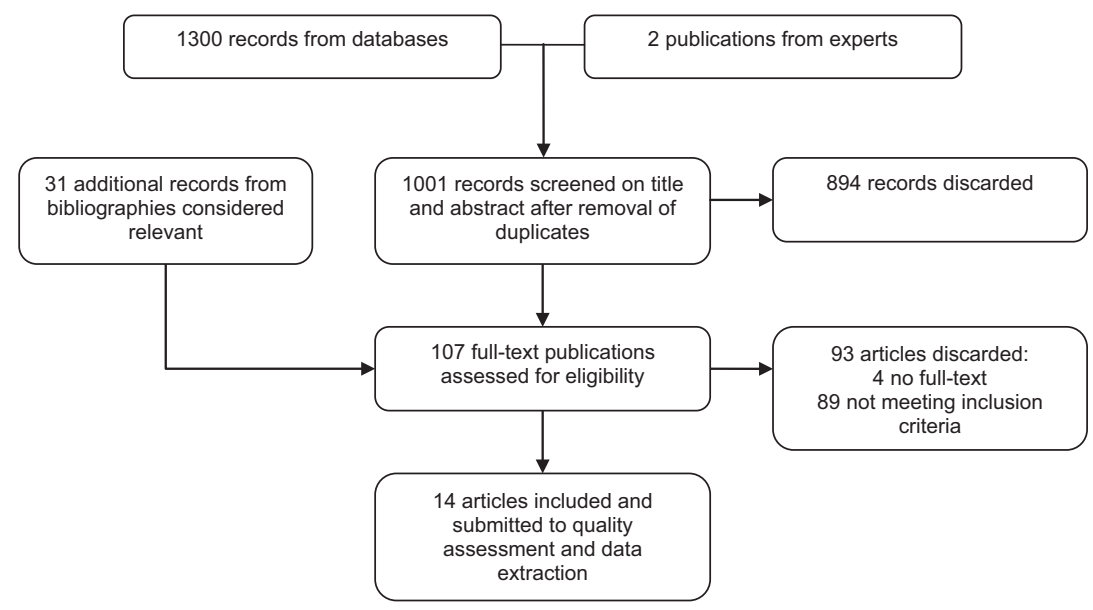

Figure 1 Study selection. Selection process for identification of published prevalence studies on VS/UWS prevalence, according to the PRISMA Statement.

the identification of the minimally conscious state (MCS) as a distinct entity in 2002 [7] and three of these publications explicitly stated inclusion criteria which also cover MCS (e.g. visual fixation, inconsistent command following) $[33,39,45]$. Diagnoses of included patients were verified by researchers in $5 / 14$ studies $[26,33,35,42,43]$. Two groups [26,35] deployed scales specifically designed for level of consciousness determination in the post-acute setting: the Western Neuro Sensory Stimulation Profile [47] and the Wessex Head Injury Matrix [48], respectively. In the remaining three studies [33,42,43], researchers used unvalidated assessment methods, descriptive scales (e.g. the Glasgow Outcome Scale [49]) and/or scales unsuitable for level of consciousness assessment in the post-acute and long-term setting, such as the Glasgow Coma Scale [50]. Case verification was carried out within 3 days in two studies [42,43], while the time lapse between study date and assessment remained unclear in the other 3 . One study involved caregivers' and/or proxies' observations and whether consensus about the patient's's diagnosis existed between those two parties, but only verified cases in which there were doubts about the diagnosis [26]. In none of the studies, repeated assessments or complementary diagnostics, such as functional magnetic resonance imaging, seem to have been used.

Four papers discussed point prevalence $[33,37,42,43]$ and two studies reported period prevalence figures [36,41]. From 8/14 studies, it remained unclear whether a point or a period prevalence had been the objective $[26,31,32,35,38-40,51]$. The terms 'prevalence' and 'incidence' were used erroneously in three papers $[32,33,37]$. As the number of patients at a certain time point was clearly mentioned in these texts, we remained able to extract the prevalence figures.
Keeping aforementioned methodological differences in mind, the prevalence figures showed a broad variety from publication to publication. Authors of one study concluded that the prevalence in their population had to be less than $0.13 / 100000$ as there were no VS/UWS patients in a sample of 389 individuals [37]. This figure set aside because of the small sample it arose from, according to literature the prevalence of VS/UWS varies from 0.2/100 000 (the Netherlands, 2003)[26] to 6.1/ 100000 inhabitants (Lombardia, Italy 2009-10) [40].

\section{Discussion}

This systematic review of prevalence studies on VS/ UWS shows a wide range in available prevalence figures, from $0.2 / 100000$ to $6.1 / 100000$ inhabitants [26,40]. Interestingly, no publications were found from the African continent, Latin-America or Asia outside of Japan, while this last country accounted for $3 / 14$ of the publications (as did Austria and the Netherlands). The broad distribution of VS/UWS prevalence figures themselves may be attributable to various factors.

First of all, the prevalence of VS/UWS is expected to vary between and maybe even within countries due to quality and availability of emergency and intensive care services [52]. Secondly, end-of-life decisions in the intensive care unit, on hospital wards, and in postacute and long-term care settings are strongly influenced by a country's political, professional, judicial and cultural profile [53]. The Netherlands, for example, allows for withholding life-sustaining medical treatment and withdrawal of artificial nutrition and hydration (ANH) in VS/UWS once prognostic boundaries of recovery of consciousness have passed [54,55]. Between 2000 and 2003, 9 out of 43 deaths of VS/ 
UWS patients were preceded by cessation of ANH and 24 by a decision not to treat complications [26]. The low Dutch VS/UWS prevalence, 30 times smaller than what was found in the Italian study, might be partially attributable to this.

However, we believe that the considerable different ways in which the prevalence studies were carried out render it impossible to draw legitimate conclusions on this sensitive subject. This brings us to a third explanation of the differences in VS/UWS prevalence. What the assessment of the included studies' methodological quality reflects, is the challenge of shedding light on a relatively small, silent group of patients who mostly live in long-term care facilities. Those being cared for at home form an even more difficult population to reach.The absence of a gold standard for the diagnosis of VS/ UWS is another complicating factor. In this context, it is understandable that only $5 / 14$ prevalence figures were (partly) based on verified cases, none according to current expert recommendations. This fact, combined with the possibility that the $9 / 14$ studies pre-dating the definition of the minimally conscious state (MCS) in 2002 [7] may have resulted in a combined prevalence of MCS and VS/UWS together, undermines the reliability of available prevalence figures on VS/UWS. Both inclusion of MCS and failure to identify signs of consciousness might lead to a substantial overestimation of the actual number of VS/UWS patients in reported publications, while incomplete coverage of the various care settings may also cause underestimation.

To our knowledge, only one systematic review has evaluated the prevalence of the VS/UWS before [56]. It showed heterogeneity in both methodology and outcomes, which our study confirms. However, in contrast, we found 14 instead of five eligible prevalence studies and were able to assess the methodological quality of studies and their context as well. These differences can be attributed to a more extensive literature search and the use of established quality criteria for prevalence studies in our study.

A limitation to our study is that four possibly relevant papers [27-30] could not be retrieved, despite attempts to contact the authors and publishers. One of these records is an early Japanese study, in which authors of two studies we did include, were involved [27]. The abstracts nor contents of the other three have been clarified.

In conclusion, the VS/UWS prevalence figures which keep appearing in public debate, influencing health care policy and the public picture, are an unreliable representation of the actual patient population. This calls for new, nationwide point prevalence studies in which patients could be identified by addressing medical professionals in hospitals, rehabilitation cen- tres, nursing homes, facilities for people with intellectual disability and general practitioners. Inclusion criteria should cover VS/UWS due to acute brain injury at least 1 month prior to the study date, as by this time the incidence of complications related to the causative trauma or illness is expected to drop. With regards to diagnosis verification, the value of repeated measurements, which is strongly recommended in clinical practice [57,58], should be weighed against the methodological challenges of visiting patients as soon as possible after the point prevalence date. A single CRS-r assessment, for example, could be enhanced by the active involvement of proxies and caregivers who observe the patient on a daily basis. When it comes to VS/UWS, one of the most dramatic conditions we face in modern medicine, it is time to get the epidemiological facts straight.

\section{Acknowledgements}

Elmie Peters kindly assisted in constructing the search strategy. We would like to thank the Stichting Beroepsopleiding Huisartsen (SBOH) for making this research project possible. Apart from authors' salaries, no additional funding was involved in this study.

\section{Disclosure of conflict of interest}

The authors declare no financial or other conflicts of interest.

\section{Supporting Information}

Additional Supporting Information may be found in the online version of this article:

Appendix S1. Search strategies.

Appendix S2. Method of quality assessment and data extraction.

\section{References}

1. Laureys S, Celesia GG, Cohadon F, et al. Unresponsive wakefulness syndrome: a new name for the vegetative state or apallic syndrome. BMC Med 2010; 8: 68.

2. Jennett B, Plum F. Persistent vegetative state after brain damage. A syndrome in search of a name. Lancet 1972; 1: 734-737.

3. The Multi-Society Task Force on PVS. Medical aspects of the persistent vegetative state (1). $N$ Engl J Med 1994; 330: 1499-1508.

4. Bodart O, Laureys S, Gosseries O. Coma and disorders of consciousness: scientific advances and practical considerations for clinicians. Semin Neurol 2013; 33: 83-90.

5. Jennett B. The Vegetative State: Medial Facts, Ethical And Legal Dilemmas. Cambridge University Press: Cambridge, 2002. 
6. Beaumont JG, Kenealy PM. Incidence and prevalence of the vegetative and minimally conscious state. Neuropsychol Rehabil 2005; 15: 184-189.

7. Giacino JT, Ashwal S, Childs NL, et al. The minimally conscious state: definition and diagnostic criteria. Neurology 2002; 58: 349-353.

8. Andrews K, Murphy L, Munday R, Littlewood C. Misdiagnosis of the vegetative state: retrospective study in a rehabilitation unit. $B M J 1996$; 313: 13-16.

9. Schnakers C, Vanhaudenhuyse A, Giacino J, et al. Diagnostic accuracy of the vegetative and minimally conscious state: clinical consensus versus standardized neurobehavioral assessment. BMC Neurol 2009; 9: 35.

10. Giacino JT, Kalmar K. The vegetative state and minimally conscious states: a comparison of clinical features and functional outcome. J Head Trauma Rehabil 1997; 12: $36-51$.

11. Giacino JT, Kalmar K. Diagnostic and prognostic guidelines for the vegetative and minimally conscious states. Neuropsychol Rehabil 2005; 15: 166-174.

12. Voss HU, Uluc AM, Dyke JP, et al. Possible axonal regrowth in late recovery from the minimally conscious state. J Clin Invest 2006; 116: 2005-2011.

13. Boly M, Faymonville ME, Peigneux P, et al. Cerebral processing of auditory and noxious stimuli in severely brain injured patients: differences between VS and MCS. Neuropsychol Rehabil 2005; 15: 283-289.

14. Laureys S, Perrin F, Faymonville ME, et al. Cerebral processing in the minimally conscious state. Neurology 2004; 63: 916-918.

15. Jennett B. Resource allocation for the severely brain damaged. Arch Neurol 1976; 33: 595-597.

16. Graham ID, Harrison MB, Nelson EA, Lorimer K, Fisher A. Prevalence of lower-limb ulceration: a systematic review of prevalence studies. Adv Skin Wound Care 2003; 16: 305-316.

17. Loney L, Chambers LW, Bennett KJ, Roberts JG, Stratford PW. Critical appraisal of the health research literature: prevalence or incidence of a health problem. Chronic Dis Can 1998; 19: 170-176.

18. Radulescu TD, Diepgen TL, Weisshaar E, Williams H. What makes a good prevalence survey? Blackwell Publishing Website. Available at: http://www.blackwellpublishing.com/medicine/bmj/dermatology/pdfs/prevalence_survey.pdf (accessed 05/05/2004).

19. Giacino JT, Kalmar K, Whyte J. The JFK coma recovery scale-revised: measurement characteristics and diagnostic utility. Arch Phys Med Rehabil 2004; 85: 2020-2029.

20. Seel RT, Sherer M, Whyte J, et al. Assessment scales for disorders of consciousness: evidence-based recommendations for clinical practice and research. Arch Phys Med Rehabil 2010; 91: 1795-1813.

21. Tarquini D, Congedo M, Formaglio F, et al. Persistent vegetative state: an ethical reappraisal. Neurol Sci 2012; 33: 695-700.

22. Lavrijsen JCM, Van den Bosch JSG, Costongs LGP, Eilander HJ, Hoenderdaal PL, Minderhoud JM. Diagnosis of vegetative state as a basis for medical treatment on the borderline between life and death (Dutch). Ned Tijdschr Geneeskd 2003; 147: 195-198.

23. Majerus S, Gill-Thwaites H, Andrews K, Laureys S. Behavioral evaluation of consciousness in severe brain damage. Prog Brain Res 2005; 150: 397-413.
24. Monti MM, Laureys S, Owen AM. The vegetative state. BMJ 2010; 341: c3765.

25. Bruno MA, Gosseries O, Ledoux D, Hustinx R, Laureys $\mathrm{S}$. Assessment of consciousness with electrophysiological and neurological imaging techniques. Curr Opin Crit Care 2011; 17: 146-151.

26. Lavrijsen JC, van den Bosch JS, Koopmans RT, van Weel C. Prevalence and characteristics of patients in a vegetative state in Dutch nursing homes. J Neurol Neurosurg Psychiatry 2005; 76: 1420-1424.

27. Sato S, Ueki K, Arai $\mathrm{H}$, et al. Epidemiological survey of vegetative state patients in the Tohoku District, Japan-special reference to the follow-up study after one year (author's transl). Neurol Med Chir (Tokyo) 1979; 19: $327-333$.

28. Brule JF, Danze F, Vallee D. "État végétatif: problèmes thérapeutiques." Revue Francais Dommage Corporel 14, 1988.

29. Lehman LB. The persistent vegetative state. Postgrad Med 1990; 88: 150, 152.

30. Fearnside MR, Gurka JA. The challenge of traumatic brain injury. Med J Aust 1997; 167: 293-294.

31. Ashwal S, Bale JF, Coulter DL, et al. The persistent vegetative state in children: report of the Child Neurology Society Ethics Committee. Ann Neurol 1992; 32: 570-576.

32. Sato S, Ueki K, Arai $\mathrm{H}$, et al. Epidemiological survey of vegetative state patients in Tohoku district in Japan. Neurol Med Chir (Tokyo) 1978; 18(1 Pt 1): 141-145.

33. Higashi K, Sakata Y, Hatano M, et al. Epidemiological studies on patients with a persistent vegetative state. $J$ Neurol Neurosurg Psychiatry 1977; 40: 876-885.

34. Tasseau F, Boucand MH, Le Gall JR, Verspieren P. États végétatifs chroniques: répercussions humaines, aspects médicaux, juridiques et éthiques. Rennes: Ecole Nationale de la Santé Publique, 1991.

35. Saout V, Ombredane MP, Mouillie JM, Marteau C, Mathe JF, Richard I. Patients in a permanent vegetative state or minimally conscious state in the Maine-et-Loire county of France: a cross-sectional, descriptive study. Ann Phys Rehabil Med 2010; 53: 96-104.

36. Donis J, Kräftner B. The prevalence of patients in a vegetative state and minimally conscious state in nursing homes in Austria. Brain Inj 2011; 25: 1101-1107.

37. Engberg AW, Teasdale TW. A population-based study of survival and discharge status for survivors after head injury. Acta Neurol Scand 2004; 110: 281-290.

38. Plexus Medical Group. Ontwaken uit ontwetendheid verslag van een onderzoek naar de situatie van comapatiënten in Nederland: de zorg, de organisatie, de begeleiding. Report, 1998.

39. Kodama N, Suzuki J. Vegetative state patients in Japan. Neurol Med Chir (Tokyo) 1976; 16(PT1): 155-160.

40. Pistarini C, Lispi L, Ceccolini C, et al., Burden of the vegetative state in Italy. Brain Inj. Conference: 8th World Congress on Brain Injury of the International Brain Injury Association Washington, DC United States. Conference Start: 20100310 Conference End: 20100314. Conference Publication: (var.pagings). 2010; 24: 120-121.

41. Plexus Medical Group. Ontwaken uit onwetendheid; verslag van een onderzoek naar de situatie van comapatienten in Nederland: de zorg, de organiasatie, de begeleiding. 1998. 
42. Stepan C, Haidinger G, Binder H. Prevalence of persistent vegetative state/apallic syndrome in Vienna. Eur $J$ Neurol 2004; 11: 461-466.

43. Stepan C, Zaunbauer L, Haidinger G, Binder H. Prevalence of Apallic Syndrome (Vegetative State) in Vienna - Comparison with results found in 2001 [German]. Neurol Rehabil 2006; 12: 320-323.

44. Leonardi M, Sattin D, Raggi A. An Italian population study on 600 persons in vegetative state and minimally conscious state. Brain Inj 2013; 27: 473-484.

45. Sato S, Ueki K, Arai H, et al. Epidemiological survey of vegetative state patients in Tohoku district in Japan. Neurol Med Chir 1978; 18: 141-145.

46. Minderhoud JM, Braakman R. Het vegeterende bestaan. Ned Tijdschr Geneeskd 1985; 129: 2385-2388.

47. Ansell BJ, Keenan JE. The western neuro sensory stimulation profile: a tool for assessing slow-to-recover head-injured patients. Arch Phys Med Rehabil 1989; 70: 104-108.

48. Shiel A, Horn SA, Wilson BA, Watson MJ, Campbell MJ, McLellan DL. The Wessex Head Injury Matrix (WHIM) main scale: a preliminary report on a scale to assess and monitor patient recovery after severe head injury. Clin Rehabil 2000; 14: 408-416.

49. Jennett B, Bond M. Assessment of outcome after severe brain damage: a practical scale. Lancet 1975; 1: 480-484.

50. Teasdale G, Jennett B. Assessment of coma and impaired consciousness: a practical scale. Lancet 1974; 2: $81-84$.
51. Minderhoud JM, Braakman R. The vegetative existence. Ned Tijdschr Geneeskd 1985; 129: 2385-2388.

52. Kohnen RF, Lavrijsen JC, Bor JH, Koopmans RT. The prevalence and characteristics of patients with classic locked-in syndrome in Dutch nursing homes. $J$ Neurol 2013; 260: 1527-1534.

53. Sprung CL, Cohen SL, Sjokvist $\mathrm{P}$, et al. End-of-life practices in European intensive care units: the Ethicus Study. JAMA 2003; 290: 790-797.

54. Health Council of The Netherlands: Committee on Vegetative State. Patients in a Vegetative State. Health Council of the Netherlands: The Hague, 1994.

55. KNMG (Royal Dutch Medical Association) Commissie Aanvaardbaarheid Levensbeëindigend handelen. Medisch handelen rond het levenseinde bij wilsonbekwame patiënten (Medical End-of-Life Practice for Incompetent Patients: Patients in a Vegetative State) [in Dutch]. Houten/Diegem: Bohn Stafleu Van Loghum. 1997: 77-104.

56. Pisa FE, Biasutti E, Drigo D, Barbone F. The prevalence of vegetative and minimally conscious states: a systematic review and methodological appraisal. J Head Trauma Rehabil 2013; [Epub ahead of print].

57. Wade DT, Johnston C. The permanent vegetative state: practical guidance on diagnosis and management. $B M J$ 1999; 319: 841-844.

58. Godbolt AK, Stenson S, Winberg M, Tengvar C. Disorders of consciousness: preliminary data supports added value of extended behavioural assessment. Brain Inj 2012; 26: 188-193. 